\title{
S100A10: A Key Regulator of Fibrinolysis
}

\author{
Alexi P. Surette and David M. Waisman \\ Additional information is available at the end of the chapter
}

\section{Introduction}

Regulation of fibrinolytic activity can be achieved by several mechanisms, ranging from regulating the production and localization of the plasminogen activators and their inhibitors, the degradation and inactivation of plasmin via autoproteolysis, and the synthesis and localization of the cell surface receptors for plasminogen. Binding of the inactive zymogen plasminogen to its cell surface receptors has been shown to significantly increase the rate of its conversion to the active serine-protease plasmin by co-localizing plasminogen with its activators, the tissue-type plasminogen activator (tPA) and the urokinase-type plasminogen activator (uPA) [1-3].One such cell surface plasminogen receptor is S100A10 (p11) [4]. S100A10, a member of the S100 protein family, was initially discovered as an annexin A2 (p36) binding partner [5-7]. S100A10 has also been found to interact with other cellular proteins including the Rho GTPase-activating protein DLC1 [8], cytosolic phospholipase A2 [9], the serotonin $1 \mathrm{~B}$ receptor [10] and various ion channels, including the potassium channel TASK-1 [11], the sodium channel $\mathrm{Na}(\mathrm{V}) 1.8$ [12] and the calcium channels TRPV5 and TRPV6 [13]. However, the major binding partners of S100A10 on the cell surface are tPA and plasminogen [14]. The focus of this review will be to discuss the role that extracellular S100A10 plays in regulating the conversion of plasminogen to plasmin and the physiological consequences of that process (Figure 1).

S100A10 is found on the cell surface as part of the annexin A2 heterotetramer complex (AIIt) [15]. AIIt is composed of two annexin A2 (p36) subunits along with two S100A10 subunits which form a $\mathrm{p} 36_{2} / \mathrm{p} 11_{2}$ complex. Initially, annexin A2 was proposed to exist as a monomer on the cell surface where it functioned as a plasminogen receptor [16,17]. The possibility that S100A10 was present on the cell surface was ruled out by these investigators who reported that S100A10 was not present on the cell surface [18]. Subsequently, it was firmly established that S100A10 was present on the cell surface and this S100A10 was shown to exist as a complex with annexin A2 [15]. In view of this report, the proposed role of annexin A2 as a plasminogen 


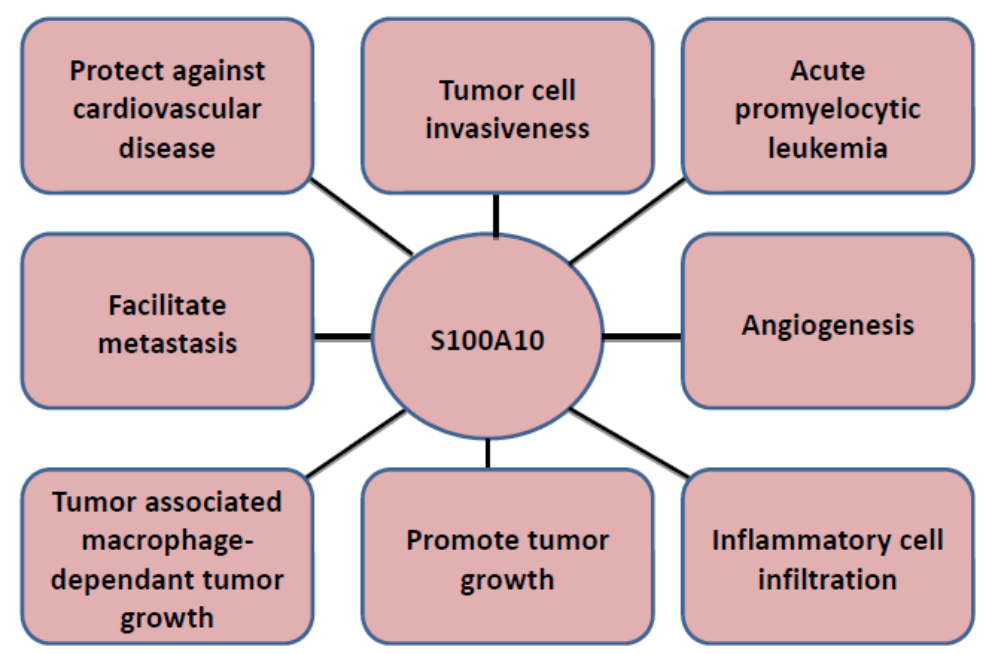

Figure 1. Roles of cell surface S100A10 in pathological processes. S100A10 on the cell surface participates in several pathological processes. S100A10 mediated fibrinolysis can have protective effects against cardiovascular disease and can participate in necessary inflammatory processes. Conversely, S100A10 mediated fibrinolysis may also participate in pathological inflammation and promote tumorigenesis through several mechanisms, including TAM infiltration, angiogenesis, tumor cell invasiveness and metastasis.

receptor was revised and it was reported that within the $\mathrm{p} 36_{2} \mathrm{p} 11_{2}$ complex, annexin A2 acted as the plasminogen receptor [19]. However, more rigorous studies have indicated that while annexin A2 does in fact anchor the p $36_{2} / \mathrm{p} 11_{2}$ complex to the cell surface in a calcium dependent fashion, S100A10 acts as the plasminogen receptor [14,15,20,21] (Figure 2).

Several cell surface proteins have been identified as plasminogen receptors, including histone 2B [22,23], integrin $\alpha_{\mathrm{M}} \beta_{2}$ [24], $\alpha$-enolase [25], cytokeratin-B [26,27] and Plg- $\mathrm{R}_{\mathrm{TK}}$ [28]. All of these cell surface plasminogen receptors contain carboxyl-terminal lysines, which interact with the kringle domains of plasminogen [29-33]. Within the $\mathrm{p} 36_{2} / \mathrm{p} 11_{2}$ complex only S100A10 contains a carboxyl-terminal lysine. Binding studies using surface plasmon resonance demonstrated that S100A10 binds to plasminogen $\left(\mathrm{K}_{\mathrm{d}}=1.81 \mu \mathrm{M}\right)$ while annexin A2 does not bind plasminogen. Interestingly, the $\mathrm{p} 36_{2} / \mathrm{p} 11_{2}$ complex binds plasminogen with higher affinity $\left(\mathrm{K}_{\mathrm{d}}=0.11 \mu \mathrm{M}\right)$ than S100A10 alone, indicating that annexin A2 may induce a conformational change in S100A10 that facilitates the interaction of S100A10 with $\mathrm{PPA}$ or plasminogen. Treatment of both S100A10 and the $\mathrm{p} 36_{2} / \mathrm{p} 11_{2}$ complex with carboxypeptidase $\mathrm{B}$, which removes carboxyl-terminal lysines, abolished plasminogen binding, indicating that plasminogen binding to the $\mathrm{p} 3 \mathrm{6}_{2} /$ p $11_{2}$ complex was dependent on the carboxyl-terminal lysine present on S100A10 [4,34]. S100A10 increased the rate of tPA dependent plasmin activation 46 -fold while the $\mathrm{p} 36_{2} / \mathrm{p} 11_{2}$ complex increased the rate of activation 77-fold. Annexin A2, on the other hand, only increased the rate of activation 2-fold, indicating that S100A10 participates in plasminogen binding and subsequent generation of plasmin [21]. In the original studies in which purified annexin A2 


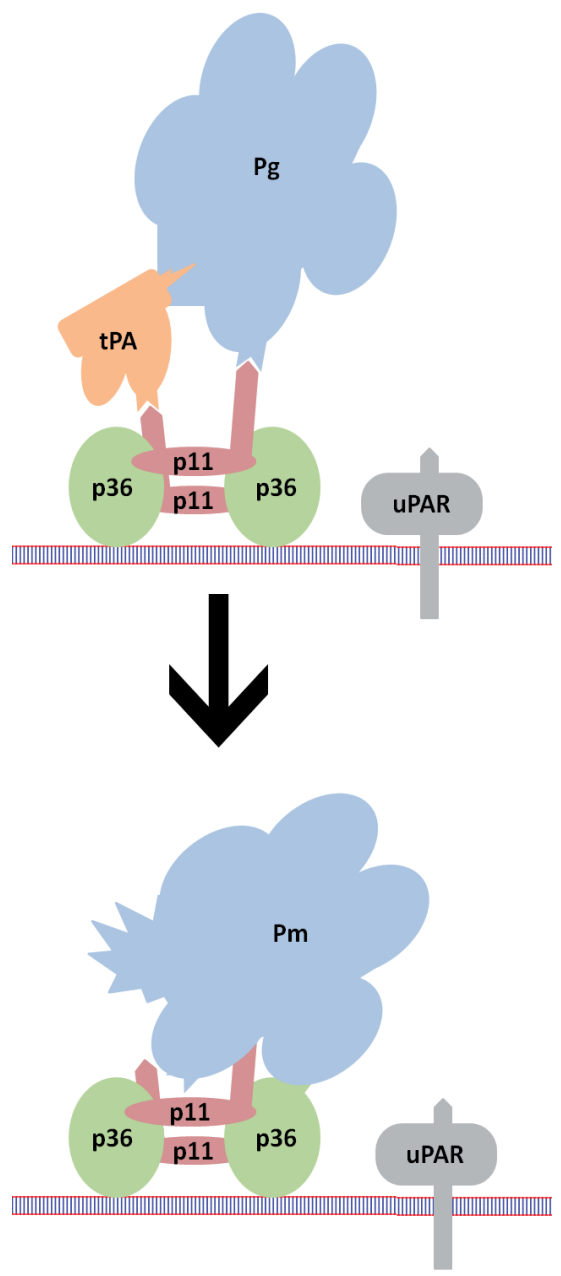

Figure 2. Model depicting Allt dependant plasmin generation Allt is composed of two annexin A2 (p36) monomers and two S100A10 (p11) monomers. Annexin A2 anchors Allt to the cell membrane through phospholipid binding sites. Plasminogen (Pg) and tPA bind to S100A10 in a carboxyl-terminal lysine dependant fashion. Allt also co-localizes with uPAR on the cell membrane. Binding of plasminogen to S100A10 therefore brings it into close proximity with the plasminogen activators TPA and UPA, accelerating proteolytic activation of plasminogen into the active serine protease plasmin (Pm). Plasmin binds to Allt through annexin A2 and S100A10 in a non-carboxyl-terminal lysine dependant fashion.

was demonstrated to bind plasminogen, carboxypeptidase B treatment of this annexin A2 was observed to block plasminogen binding. Since annexin A2 does not possess a carboxyl-terminal lysine, a cleavage event at Lys307-Arg308 of annexin A2 was postulated to occur, thereby 
exposing the prerequisite carboxyl-terminal lysine for plasminogen binding [35]. However, this cleavage event has never been demonstrated to occur in vitro or in vivo. In contrast, carboxyl-terminal lysines are present on S100A10 and therefore do not require post-translational modification. Furthermore, Plow's group demonstrated that an antibody generated against the K327-D338 region of annexin A2 inhibits plasmin generation, suggesting that the carboxyl-terminus of annexin A2 remains intact during plasmin generation and therefore that the putative cleavage event does not occur [36]. The crystal structure of annexin A2 has revealed that the amino- and carboxyl-terminal regions of annexin A2 are present in a cleft in the concave surface of annexin A2 in close proximity to S100A10. Surprisingly the possibility that the annexin A2 antibody might affect the conformation of S100A10 was not considered.

In addition to binding plasminogen, the carboxyl-terminal lysines of S100A10 form the binding site for tPA [21]. Since the $\mathrm{p} 36_{2} / \mathrm{p} 11_{2}$ complex also co-localizes with the uPA receptor, uPAR, at the cell surface [15], binding of plasminogen to S100A10 brings plasminogen into close proximity to both plasminogen activators on the cell surface, thereby dramatically increasing the rate of conversion of plasminogen to plasmin.

\section{Role of S100A10 in fibrinolysis}

Conversion of plasminogen to plasmin contributes to the maintenance of vascular patency, as the serine-protease plasmin Is the principle enzyme responsible for degrading fibrin, the main protein component of blood clots. Cell surface plasminogen receptors, which play a critical role in the activation of plasminogen, therefore participate in the clearance of potentially dangerous blood clots. The advent of annexin A2 (annexin A2-/-) and S100A10 knock-out (S100A10-/-) mice have provided valuable tools to investigate the in vivo role of the $\mathrm{p} 36_{2} /$ $\mathrm{p} 11_{2}$ complex in fibrinolysis. As discussed, previous reports had suggested that annexin A2 was responsible for the generation of plasmin and subsequent fibrinolysis [16,35,37]. However, since annexin A2 is responsible for stabilization of S100A10 levels [38], loss of annexin A2 can be regarded as loss of both annexin A2 and S100A10. For example, studies conducted with the annexin A2 knockout mouse and with shRNA knockdown of annexin A2 in cultured cells have established that the S100A10 levels are uniquely sensitive to the annexin A2 levels and that depletion of cellular annexin A2 results in the concomitant depletion of S100A10 [8,38,39]. It is therefore impossible to determine whether annexin A2 or S100A10 is responsible for plasmin generation in the annexin A2 knockout mouse model.

Since annexin A2 is present on the cell surface of S100A10-/- endothelial cells [39], we can conclude that alterations in plasminogen binding and plasmin activation in this model are due to loss of S100A10. The S100A10-/- mouse is therefore helpful in clarifying the mechanism by which the $\mathrm{p} 36_{2} / \mathrm{p} 11_{2}$ complex participates in fibrinolysis and neoangiogenesis [39]. This model revealed a significant increase in fibrin deposits in the lung, liver, kidney and spleen of the S100A10-/- mouse [39]. S100A10 was also shown to play an important role in the clearance of microvascular thrombi as the S100A10-/- mouse had an impaired ability to clear blood clots induced by the thrombin-like enzyme batroxobin. Clots formed after the experimental 
induction of vascular damage using the tail-clip assay were also more stable in the S100A10-/ - mouse. Since the wild-type and S100A10-/- mice shared similar coagulation parameters, the observed reduction in bleeding time after tail clipping of the S100A10-/- mice was due to decreased fibrinolysis of the tail clip-induced blood clot. The time between cessation of bleeding and the initiation of subsequent episodes of bleeding, the rebleeding time, was of shorter duration and less frequent with the S100A10-/ mice, thus the clots formed by the S100A10-/- mice were more stable than the wild-type mice, again due to a decreased rate of fibrinolysis. S100A10 therefore plays a critical role in the fibrinolytic surveillance system which functions to maintain vascular patency. Failure of this system contributes to the pathogenesis of cardiovascular disease, including deep vein thrombosis, stroke, atherosclerosis and coronary heart disease.

Endothelial cells, which line the interior lumen of blood vessels, play a critical role in maintaining vascular patency by participating in the regulation of plasmin generation. Loss of S100A10 in endothelial cells results in a 40-50\% decrease in plasminogen binding and activation, suggesting that endothelial cell S100A10 is crucial for vascular fibrinolysis and therefore plays a key role in the fibrinolytic surveillance system [39].

Other work using the S100A10-/- mouse demonstrated the role S100A10 plays in plasminogen-dependent macrophage invasion. Such invasion is critical in physiological and pathological inflammation as macrophages utilize proteases to remodel the extracellular matrix (ECM) in order to move through tissue barriers to reach sites of infection. Murine macrophages lacking S100A10 have an impaired ability to invade into the peritoneal cavity in response to inflammatory stimulation [40]. The presence of S100A10, but not annexin A2 alone, is associated with plasminogen dependent invasion by macrophages, providing further evidence that the $\mathrm{S} 100 \mathrm{~A} 10$ subunit of the $\mathrm{p} 36_{2} / \mathrm{p} 11_{2}$ complex is responsible for plasmin generation.

\section{Role of the $\mathrm{p} 36_{2} / \mathrm{p} 11_{2}$ complex in hyperhomocysteinemia}

Hyperhomocysteinemia, a condition where elevated levels of homocysteine are found in the blood, has been identified as an independent risk factor for cardiovascular disease [41-44]. Several groups have reported that elevated homocysteine levels results in endothelial cell dysfunction [45-49] and a hyperthrombotic state [41,50-52], which may provide a mechanism by which hyperhomocysteinemia contributes to cardiovascular disease. One mechanism by which homocysteine may promote a hyperthrombotic state is through an interaction with annexin A2 [42,52,53]. Homocysteine, a reactive thiol-containing amino acid produced during the conversion of methionine to cysteine [54], was postulated to form a disulfide bond with extracellular annexin A2 at Cys-8 [55]. This interaction was reported to interfere with tPA binding to annexin A2 [55], thus preventing tPA mediated plasmin generation and fibrinolysis, resulting in the accumulation of blood clots. The report of tPA forming a covalent bond with annexin A2 contradicts other reports that demonstrate tPA binding to the cell surface in a carboxyl-terminal lysine dependent fashion [56]. Results from our laboratory suggested that highly purified annexin A2 fails to bind to tPA [4]. A subsequent in vivo murine study by the 
Hajjar group expanded on how homocysteine may target annexin A2 to inhibit fibrinolysis. They purified annexin A2 from control mice and mice on a hyperhomocysteinemic diet. A comparison of this purified annexin A2 revealed that the annexin A2 isolated from the mice on a hyperhomocysteinemic diet failed to stimulate tPA-dependent plasmin activation, ie. it was totally inactive. They concluded that elevated serum homocysteine formed a disulfide bond with extracellular annexin A2 resulting in inhibition of annexin A2-dependent plasmin generation [57]. The authors failed to note that $95 \%$ of annexin A2 is present intracellularly [17] and that only $5 \%$ of the total annexin A2 would be available to interact with homocysteine present in the blood. Thus even if all of the extracellular annexin A2 was modified by homocysteine, it is unclear how a population consisting of $5 \%$ extracellular homocysteine-modified annexin A2 and 95\% unmodified intracellular annexin A2 could be completely inactive. Since the vast majority of the annexin A2 purified from murine lungs is intracellular, homocysteine would therefore have to label all or most of the intracellular annexin A2 in order to explain the in vitro results. Such labelling could also, theoretically, impact not only other annexin A2 functions but should also affect other redox-sensitive proteins and transcription factors which could contribute to endothelial cell dysfunction. It is also unclear how extracellular levels of homocysteine, which in the mouse model are unlikely to exceed $100 \mathrm{uM}$, could affect intracellular proteins since the intracellular levels of the homocysteine-reactive molecule, glutathione, is present intracellularly at levels of $10 \mathrm{mM}$. However, it seems implausible for homocysteine to label such a significant portion of intracellular annexin A2 as most homocysteine is bound to plasma proteins [58] and the effective free homocysteine concentration would be insufficient to label intracellular proteins to this extent. It therefore remains unclear how the reported interaction of annexin A2 with homocysteine may contribute to impaired fibrinolysis. Interestingly, a recent report appears to contradict the Hajjar model for homocysteinemia. The Lentz group investigated transgenic mice deficient for the cystathionine $\beta$ synthase (CBS), the enzyme responsible for metabolizing homocysteine to cystathionine. In humans, CBS deficiency causes severe hyperhomocysteinemia and this animal model is therefore representative of human disease. Loss of CBS did in fact result in endothelial dysfunction in these animals. However, CBS deficiency did not result in a prothrombotic phenotype. In fact the CBS-null animals displayed normal rates of fibrinolysis [59]. Since these authors were unable to reproduce the findings of the Hajjar study $[57,60]$, they speculated that the prothrombotic phenotype observed in diet-induced hyperhomocysteinemia might not be due to elevated homocysteine but possibly due to other dietary metabolites.

The difficulty in reproducing the Hajjar study was recently discussed by Jakubowski [61]. He pointed out that if homocysteinylation of annexin A2 generates a prothrombotic phenotype, it should be observed in any model of hyperhomocysteinemia, regardless of whether the model is dietary or genetic. He proposed that annexin A2 homocysteinylation for an unknown reason did not occur in the genetic model of hyperhomocysteinemia. These data therefore suggest that annexin A2 does not play a physiologically relevant role in hyperhomocysteinemia in humans.

In humans, CBS deficiency results in severe hyperhomocysteinemia, where plasma homocysteine levels are in excess of $100 \mu \mathrm{M}$. Treatment of these patients with B vitamins reduces plasma 
homocysteine to $30-80 \mu \mathrm{M}$, which is still higher than the normal $10 \mu \mathrm{M}$, and reduces the risk of thrombotic events significantly [62]. Mild to moderate hyperhomocysteinemia, where plasma homocysteine levels vary from 16-100 $\mu \mathrm{M}$ [63], is more common and can be influenced by diet and lifestyle. Treatment of mild to moderate hyperhomocysteinemia with B vitamins results in a decrease in serum homocysteine to normal levels. This decrease, however, does not correspond with decreased cardiovascular disease [64-68]. These human studies support the notion that hyperhomocysteinemia does not create a prothrombotic state and brings into question whether homocysteine targets annexin A2 in order to create a prothrombotic state. Therefore, the current evidence. The current evidence repudiates the theory that the pathological effects of hyperhomocysteinemia are due to targeting of cell surface annexin A2 and the subsequent loss of tPA binding potential resulting in impaired fibrinolysis.

\section{Role of S100A10 in cancer}

Alterations in fibrinolytic activity contribute to the pathogenesis of a wide variety of diseases. Excessive fibrinolytic activity has been associated with the pathogenesis of acute promyelocytic leukemia (APL) [69]. APL is caused by a chromosomal translocation that results in the presence of the PML-RAR- $\alpha$ fusion protein. Treatment with all-trans retinoic acid (ATRA) has greatly improved outcomes for patients with APL, in part by decreasing the hyper-fibrinolytic state associated with the disease. A role for annexin A2 in the pathogenesis of APL was proposed based on the discovery that annexin A2 levels increased as a result of this fusion protein and treatment with ATRA reduced annexin A2 levels, potentially resulting in reduced fibrinolytic activity [70,71]. Subsequent studies indicated that annexin A2 was actually present in a complex with S100A10 on the cell surface of most cells, that annexin A2 stabilized S100A10 protein levels [72] and that the S100A10 subunits of the $\mathrm{p} 36_{2} \mathrm{p} 11_{2}$ complex were responsible for plasminogen binding and activation [15,21], our group decided to explore if annexin A2 existed as a complex with S100A10 on the surface of APL cells and if so whether this S100A10 contributed to the hyper-fibrinolytic state presented in APL. We established the presence of S100A10 as a p36 ${ }_{2}$ p $11_{2}$ complex on the surface of APL cells. Next, we showed that treatment of NB4 cells, an APL cell line, with ATRA resulted in decreased total and cell surface annexin A2 and S100A10 protein levels while mRNA levels were not affected. $\alpha$-enolase and histone H2B, two other myeloid cell plasminogen receptors, were unaffected by ATRA treatment, providing further evidence that the $\mathrm{p} 36_{2} \mathrm{p} 11_{2}$ complex was the primary plasminogen receptor that contributed to hyperfibrinolysis in APL. Interestingly, the drop in S100A10 protein levels preceded that of annexin A2. This delay was observed in total protein levels as well as in cell surface protein levels, providing an opportunity to observe whether fibrinolyic activity decreased with loss of cell surface S100A10 alone or whether loss of the complete p36 ${ }_{2} \mathrm{p} 11_{2}$ complex was required to decrease fibrinolytic activity following ATRA treatment. Decreases in plasminogen binding, plasmin generation and plasminogen dependent cell invasion were not dependent on the loss of cell surface annexin A2, as these decreases only corresponded with loss of cell surface S100A10. Further evidence that S100A10 was responsible for increased fibrinolysis in APL cells was provided by silencing S100A10 expression using shRNA. Loss of 
S100A10 following shRNA expression did not alter cell surface annexin A2 levels but significantly impacted plasminogen binding, plasmin generation and invasion. In order to further explore the relationship between PML-RAR- $\alpha$ and $\mathrm{p} 36_{2} \mathrm{p} 11_{2}$ complex levels, PML-RAR- $\alpha$ expression was induced in the U937/PR-9 cell line, a myeloid cell line with a $\mathrm{ZnSO}_{4}$ inducible PML-RAR- $\alpha$ promoter. Induction of PML-RAR- $\alpha$ did in fact increase total and cell surface annexin A2 and S100A10 protein levels, yet this effect was not transcriptionally regulated as mRNA levels for each of these proteins were not impacted by PML-RAR- $\alpha$ expression. This increase in the $\mathrm{p} 36_{2} \mathrm{p} 11_{2}$ complex levels resulted in increased fibrinolytic activity. This provided a clear link between PML-RAR- $\alpha$ expression and increased levels of the p36 2 p $11_{2}$ complex. Subsequent depletion of S100A10 by shRNA in these cells mimicked the previous results observed in the NB4 cells, as plasminogen binding, plasmin stimulation and invasion were decreased with the loss of S100A10 while cell surface annexin A2 levels were unaltered [69]. This study clarified how the $\mathrm{p} 36_{2} \mathrm{p} 11_{2}$ complex participates in APL hyperfibrinolyis and demonstrates how elevation in S100A10 contributed to the pathogenesis of APL.

Plasmin proteolytic activity has long been associated with tumorigenesis [73,74]. Plasmin mediated proteolysis remodels the tumor microenvironment to permit tumor growth and degrades the basement membrane to permit cancer cell invasion through the stroma and metastasis to other organs. Plasmin directly degrades basement membrane matrix components such as fibronectin [75] and laminin [76] while also activating other proteases, including matrix metalloproteinases (MMP) -1 and -9 [77-80], to trigger a proteolytic cascade necessary for invasion through the basement membrane. Expression of the uPA-uPAR system is considered a prognostic biomarker for several types of malignancies, including breast carcinoma [81], gastric cancer [82], prostate cancer [83] and lung cancer [84]. As components of the plasmin generating system, such as uPAR, are also associated with tumor progression, the key question has been whether the $\mathrm{p} 36_{2} \mathrm{p} 11_{2}$ complex mediates plasmin generation by cancer cells and if so, does plasmin generated by the $\mathrm{p} 36_{2} \mathrm{p} 11_{2}$ complex contribute to tumor growth, invasion and metastasis. Multiple reports demonstrated increased annexin A2 expression in a variety of malignancies, which was frequently associated with poor prognosis [85-88]. These reports, however, did not investigate whether S100A10 levels were also associated with these malignancies. As work demonstrating that the carboxyl-terminal lysine of S100A10 was responsible for plasminogen binding and plasmin generation emerged, studies were conducted to observe whether S100A10-dependent plasmin generation contributed to increased invasiveness and tumorigenesis of cancer cells. Our laboratory reported that loss of S100A10 decreased the ability of HT-1080 fibrosarcoma cells [89] and CCL-222 colorectal cancer [90] to invade through an extracellular matrix and that S100A10-depleted cells displayed decreased plasminogen binding, plasmin generation and plasminogen-dependent cellular invasion. In the study with HT-1080 cells, loss of S100A10 significantly decreased the ability of these cancer cells to form metastatic lung foci while over-expression of S100A10 in these same cells increased the metastatic potential, as demonstrated by increased development of metastatic lung foci. More recently, the Zimonjic group reported that DLC1, a Rho GTPase-activating protein and known tumor suppressor, interacted with S100A10 in non small cell lung carcinoma cell lines. DLC1 competed with S100A10 for a common binding site on annexin A2. The DLC1-S100A10 interaction resulted in depletion of S100A10 protein levels as DLC1 prevented the inhibition 
of ubiquitin-dependent degradation of S100A10 by annexin A2. Depletion of S100A10 protein levels as a result of this interaction with DLC1 attenuated plasmin generation, migration, invasion through a matrigel extracellular matrix barrier and soft agar colony formation. Part of DLC1's tumor suppressor activity is therefore due to its role in decreasing S100A10 protein levels. Since DLC1-S100A10 interaction did not alter annexin A2 protein levels, this study provided further evidence that S100A10 dependent plasmin generation contributes to oncogenesis [8]. Tumor suppressor proteins such as DLC1 function by preventing normal cells from converting into cancer cells ie. they block the process of oncogenesis. Conceptually, this study was important because it linked the aberrant regulation of S100A10 protein levels with the process of oncogenesis.

In human studies, S100A10 has been identified as a tumor biomarker in several different malignancies. For example, S100A10 is associated with aggressive anaplastic carcinoma [91,92], as a marker for renal cell carcinoma [93], advanced diffuse large B-cell lymphoma [94], colorectal cancer [95], non-small cell lung carcinoma [96] and late stage aggressive gallbladder cancer [97]. Additionally, the S100A10 gene location has been identified as genomic region susceptible to epigenetic changes associated with cancer development, indicating the mechanisms associated with regulating S100A10 expression may be associated with malignancy [98]. Such associations between S100A10 levels and cancer development may correlate with cell culture and mouse studies suggesting S100A10 dependent plasmin generation facilitates tumor progression and metastasis.

Numerous studies have found associations between annexin A2 expression and tumorigenesis. These studies have proposed varying mechanisms by which annexin A2 may contribute to cancer development. Many groups maintain that annexin A2 directly interacts with plasminogen and this interaction leads to plasmin generation and subsequent plasmin mediated invasion and tumor growth. However, the majority of these studies fail to investigate whether S100A10 levels fluctuate with varying levels of annexin A2 [99-104], as would be expected by the reports demonstrating that annexin A2 protects S100A10 from ubiquitin dependent degradation [8]. Other studies have found that annexin A2 contributes to tumor progression by mechanisms other than increased plasmin generation. Annexin A2 regulates cell cycle progression by preventing G2 arrest in p53-dependent and -independent mechanisms in non-small cell lung cancer cells [105]. This provided a potential mechanism by which annexin A2 contributes to cell proliferation, which had been reported in several previous reports [102,106-109]. Annexin A2 may also contribute to tumorigenesis by protecting cancer cells from oxidative damage. Depletion of annexin A2 lead to increased levels of reactive oxygen species (ROS) and subsequent increased activation of ROS-induced proapoptotic kinases and cellular damage and resulting death. This study also demonstrated that annexin A2 increased cancer cell growth by preventing cellular protein oxidation, and elevations of reduced annexin A2 in human tumor samples correlated with reduced protein oxidation [110]. In addition to protein oxidation, ROS are also capable of mediating DNA damage [111]. Genotoxic agents, which are used in some chemotherapies, can cause DNA damage and subsequent cell death. Some genotoxic agents directly target and damage DNA, while other rely on the production of intracellular ROS that results from their metabolism [112]. Annexin 
A2 levels increase in response to increased ROS [110]. Following increased ROS levels as a result of treatment with genotoxic agents, annexin A2 accumulates in the nucleus. Increased nuclear annexin A2 levels protected the cells from DNA damage following treatment with various genotoxic agents [113]. Elevated levels of annexin A2, through its redox functions, may therefore protect cancer cells from chemotherapeutic treatment. These studies demonstrate non-plasmin dependent mechanisms by which annexin A2 may directly contribute to tumor progression and poor prognosis (Figure 3).

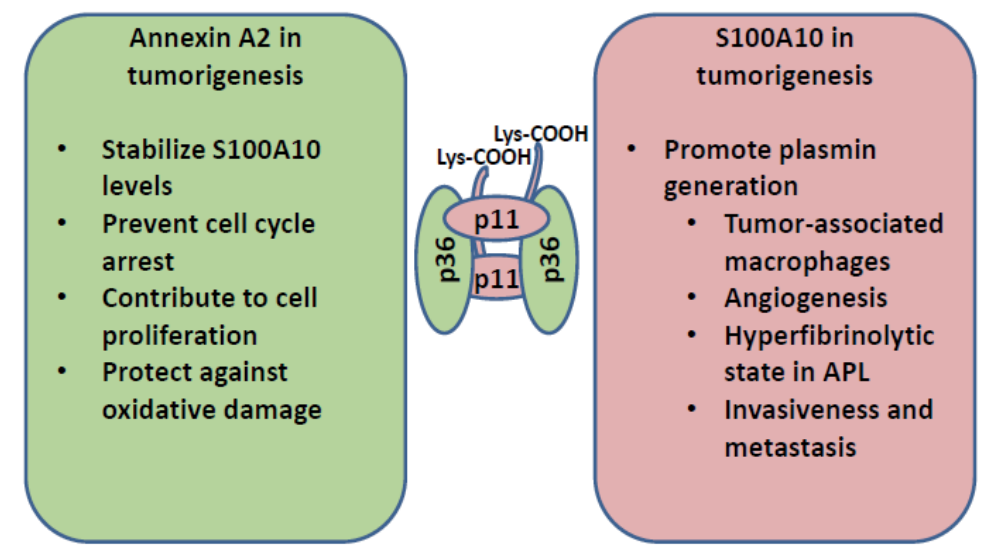

Figure 3. Roles of annexin A2 and S100A10 in tumorigenesis. Annexin A2 and S100A10 may promote tumorigenesis through several mechanisms. Annexin A2 contributes to tumorigenesis by stabilizing S100A10 levels, prevents cell cycle arrest, promotes cell proliferation and protects cancer cells from oxidative damage. S100A10 participates in tumorigenesis primarily by promoting plasmin generation, which contributes to TAM infiltration, angiogensis, invasiveness and metastasis and the hyperfibrinolytic state present in APL.

Tumor development and growth is a dynamic process that is dependent on stromal cells in addition to the cancer cells themselves. Tumor-associated macrophage (TAM) have been demonstrated to participate in tumor development [114], and increased TAM density within a solid tumor is associated with poor prognosis [115]. TAM infiltration into a growing tumor is dependent on the presence of S100A10 on the cell surface, presumably requiring the plasmin generated by the presence of S100A10 to remodel the ECM of the growing tumor and infiltrate into it. Tumor growth is impaired in S100A10-/- mice, and this impairment is due to an inability of TAM to invade into a growing tumor. Introduction of macrophages containing S100A10 into S100A10-/- mice rescued tumor growth, as did injection of S100A10 containing macrophages directly into growing tumors in S100A10-/- mice [116].

Angiogenesis, the process where a growing tumor is vascularized by endothelial cells in order to obtain a blood supply, has also been demonstrated to utilize the protease plasmin for proper angiogenesis associated ECM remodelling [117]. S100A10 dependent plasminogen activation promotes angiogenesis, as shown by decreased angiogenesis in tumors grown in the 
S100A10-/- mouse and by a decreased ability of endothelial cells lacking S100A10 to invade through matrigel, an ECM substrate similar to that found in solid tumors [39]. These results clarify a previous study where annexin A2 dependent plasmin generation was postulated to contribute to angiogenesis [37]. Therefore, this study merely recapitulated the importance of annexin A2 in the regulation of S100A10 levels and how this function of annexin A2 often leads to the misassignment of S100A10-dependent functions to annexin A2.

Recently, both components of the $\mathrm{p} 36_{2} \mathrm{p} 11_{2}$ complex were demonstrated to mediate cell-cell interactions. S100A10 on the surface of endothelial cells was shown to bind to annexin A2 on the surface of breast cancer cells, indicating an additional mechanism by which these proteins may contribute to angiogenesis [118]. S100A10 dependent plasminogen binding and subsequent plasmin generation therefore contributes to tumor growth my a variety of different mechanisms, ranging from cancer cell remodelling of the tumor microenvironment to TAM and endothelial cell invasion into a growing tumor.

\section{Conclusion}

The involvement of S100A10 in the fibrinolytic surveillance system has been well documented. The recent demonstration of the regulation of S100A10 protein levels by oncogenes and tumor suppressor proteins suggest that S100A10 also plays a central role in cellular transformation. Since S100A10 is predominately an intracellular protein, proper spatio-temporal regulation of this protein is critical to the progression of pathological processes. Therefore, through its ability to bind plasminogen and tPA, S100A10 participates in hemostasis and oncogenesis and this makes S100A10 an attractive therapeutic target for diseases ranging from cancer to cardiovascular disease.

\section{Acknowledgements}

Supported by the Heart and Stroke Foundation of Nova Scotia

\section{Author details}

Alexi P. Surette ${ }^{1}$ and David M. Waisman ${ }^{1,2^{*}}$

*Address all correspondence to: david.waisman@dal.ca

1 Department of Pathology, Dalhousie University, Halifax, NS, Canada

2 Department of Biochemistry \& Molecular Biology, Halifax, NS, Canada 


\section{References}

[1] Herren T, Swaisgood C, Plow EF. Regulation of plasminogen receptors. Front Biosci J Virtual Libr. 2003 Jan 1;8:d1-8.

[2] Collen D. The Plasminogen (Fibrinolytic) System. Thromb Haemost. 1999 Aug;82(2): 259-70.

[3] Plow EF, Felez J, Miles LA. Cellular regulation of fibrinolysis. Thromb Haemost. 1991 Jul 12;66(1):32-6.

[4] MacLeod TJ, Kwon M, Filipenko NR, Waisman DM. Phospholipid-associated annexin A2-S100A10 heterotetramer and its subunits: characterization of the interaction with tissue plasminogen activator, plasminogen, and plasmin. J Biol Chem. 2003 Jul $11 ; 278(28): 25577-84$.

[5] Gerke V, Weber K. Calcium-dependent conformational changes in the 36-kDa subunit of intestinal protein I related to the cellular 36-kDa target of Rous sarcoma virus tyrosine kinase. J Biol Chem. 1985 Feb 10;260(3):1688-95.

[6] Gerke V, Weber K. Identity of p36K phosphorylated upon Rous sarcoma virus transformation with a protein purified from brush borders; calcium-dependent binding to non-erythroid spectrin and F-actin. EMBO J. 1984 Jan;3(1):227-33.

[7] Gerke V, Weber K. The regulatory chain in the p36-kd substrate complex of viral tyrosine-specific protein kinases is related in sequence to the S-100 protein of glial cells. EMBO J. 1985 Nov;4(11):2917-20.

[8] Yang X, Popescu NC, Zimonjic DB. DLC1 interaction with S100A10 mediates inhibition of in vitro cell invasion and tumorigenicity of lung cancer cells through a RhoGAP-independent mechanism. Cancer Res. 2011 Apr 15;71(8):2916-25.

[9] Bailleux A, Wendum D, Audubert F, Jouniaux A-M, Koumanov K, Trugnan G, et al. Cytosolic phospholipase A2-p11 interaction controls arachidonic acid release as a function of epithelial cell confluence. Biochem J. 2004 Mar 1;378(Pt 2):307-15.

[10] Svenningsson P, Chergui K, Rachleff I, Flajolet M, Zhang X, El Yacoubi M, et al. Alterations in 5-HT1B receptor function by p11 in depression-like states. Science. 2006 Jan 6;311(5757):77-80.

[11] Girard C, Tinel N, Terrenoire C, Romey G, Lazdunski M, Borsotto M. p11, an annexin II subunit, an auxiliary protein associated with the background $\mathrm{K}+$ channel, TASK-1. EMBO J. 2002 Sep 2;21(17):4439-48.

[12] Okuse K, Malik-Hall M, Baker MD, Poon W-YL, Kong H, Chao MV, et al. Annexin II light chain regulates sensory neuron-specific sodium channel expression. Nature. 2002 Jun 6;417(6889):653-6. 
[13] Van de Graaf SFJ, Hoenderop JGJ, Gkika D, Lamers D, Prenen J, Rescher U, et al. Functional expression of the epithelial $\mathrm{Ca}(2+)$ channels (TRPV5 and TRPV6) requires association of the S100A10-annexin 2 complex. EMBO J. 2003 Apr 1;22(7):1478-87.

[14] MacLeod TJ, Kwon M, Filipenko NR, Waisman DM. Phospholipid-associated annexin A2-S100A10 heterotetramer and its subunits: characterization of the interaction with tissue plasminogen activator, plasminogen, and plasmin. J Biol Chem. $2003 \mathrm{Jul}$ 11;278(28):25577-84.

[15] Kassam G, Choi KS, Ghuman J, Kang HM, Fitzpatrick SL, Zackson T, et al. The role of annexin II tetramer in the activation of plasminogen. J Biol Chem. 1998 Feb 20;273(8):4790-9.

[16] Cesarman GM, Guevara CA, Hajjar KA. An endothelial cell receptor for plasminogen/tissue plasminogen activator (t-PA). II. Annexin II-mediated enhancement of tPA-dependent plasminogen activation. J Biol Chem. 1994 Aug 19;269(33):21198-203.

[17] Hajjar KA, Guevara CA, Lev E, Dowling K, Chacko J. Interaction of the fibrinolytic receptor, annexin II, with the endothelial cell surface. Essential role of endonexin repeat 2. J Biol Chem. 1996 Aug 30;271(35):21652-9.

[18] Hajjar KA, Guevara CA, Lev E, Dowling K, Chacko J. Interaction of the fibrinolytic receptor, annexin II, with the endothelial cell surface. Essential role of endonexin repeat 2. J Biol Chem. 1996 Aug 30;271(35):21652-9.

[19] Cesarman-Maus G, Hajjar KA. Molecular mechanisms of fibrinolysis. Br J Haematol. 2005 May;129(3):307-21.

[20] Kwon M, MacLeod TJ, Zhang Y, Waisman DM. S100A10, annexin A2, and annexin a2 heterotetramer as candidate plasminogen receptors. Front Biosci J Virtual Libr. 2005 Jan 1;10:300-25.

[21] Kassam G, Le BH, Choi KS, Kang HM, Fitzpatrick SL, Louie P, et al. The p11 subunit of the annexin II tetramer plays a key role in the stimulation of t-PA-dependent plasminogen activation. Biochemistry (Mosc). 1998 Dec 1;37(48):16958-66.

[22] Das R, Burke T, Plow EF. Histone H2B as a functionally important plasminogen receptor on macrophages. Blood. 2007 Nov 15;110(10):3763-72.

[23] Herren T, Burke TA, Das R, Plow EF. Identification of histone H2B as a regulated plasminogen receptor. Biochemistry (Mosc). 2006 Aug 8;45(31):9463-74.

[24] Pluskota E, Soloviev DA, Bdeir K, Cines DB, Plow EF. Integrin alphaMbeta2 orchestrates and accelerates plasminogen activation and fibrinolysis by neutrophils. J Biol Chem. 2004 Apr 23;279(17):18063-72.

[25] Miles LA, Dahlberg CM, Plescia J, Felez J, Kato K, Plow EF. Role of cell-surface lysines in plasminogen binding to cells: identification of alpha-enolase as a candidate plasminogen receptor. Biochemistry (Mosc). 1991 Feb 12;30(6):1682-91. 
[26] Hembrough TA, Li L, Gonias SL. Cell-surface cytokeratin 8 is the major plasminogen receptor on breast cancer cells and is required for the accelerated activation of cellassociated plasminogen by tissue-type plasminogen activator. J Biol Chem. 1996 Oct 11;271(41):25684-91.

[27] Gonias SL, Hembrough TA, Sankovic M. Cytokeratin 8 functions as a major plasminogen receptor in select epithelial and carcinoma cells. Front Biosci J Virtual Libr. 2001 Nov 1;6:D1403-1411.

[28] Andronicos NM, Chen EI, Baik N, Bai H, Parmer CM, Kiosses WB, et al. Proteomicsbased discovery of a novel, structurally unique, and developmentally regulated plasminogen receptor, Plg-RKT, a major regulator of cell surface plasminogen activation. Blood. 2010 Feb 18;115(7):1319-30.

[29] Hajjar KA. Cellular receptors in the regulation of plasmin generation. Thromb Haemost. 1995 Jul;74(1):294-301.

[30] Miles LA, Castellino FJ, Gong Y. Critical role for conversion of glu-plasminogen to Lys-plasminogen for optimal stimulation of plasminogen activation on cell surfaces. Trends Cardiovasc Med. 2003 Jan;13(1):21-30.

[31] Hajjar KA, Nachman RL. Endothelial cell-mediated conversion of Glu-plasminogen to Lys-plasminogen. Further evidence for assembly of the fibrinolytic system on the endothelial cell surface. J Clin Invest. 1988 Nov;82(5):1769-78.

[32] Miles LA, Plow EF. Receptor mediated binding of the fibrinolytic components, plasminogen and urokinase, to peripheral blood cells. Thromb Haemost. 1987 Oct 28;58(3):936-42.

[33] Castellino FJ, McCance SG. The kringle domains of human plasminogen. Ciba Found Symp. 1997;212:46-60; discussion 60-65.

[34] Fogg DK, Bridges DE, Cheung KK-T, Kassam G, Filipenko NR, Choi K-S, et al. The p11 subunit of annexin II heterotetramer is regulated by basic carboxypeptidase. Biochemistry (Mosc). 2002 Apr 16;41(15):4953-61.

[35] Hajjar KA, Jacovina AT, Chacko J. An endothelial cell receptor for plasminogen/ tissue plasminogen activator. I. Identity with annexin II. J Biol Chem. 1994 Aug 19;269(33):21191-7.

[36] Das R, Burke T, Plow EF. Histone H2B as a functionally important plasminogen receptor on macrophages. Blood. 2007 Nov 15;110(10):3763-72.

[37] Ling Q, Jacovina AT, Deora A, Febbraio M, Simantov R, Silverstein RL, et al. Annexin II regulates fibrin homeostasis and neoangiogenesis in vivo. J Clin Invest. 2004 Jan; 113(1):38-48. 
[38] He K-L, Deora AB, Xiong H, Ling Q, Weksler BB, Niesvizky R, et al. Endothelial cell annexin A2 regulates polyubiquitination and degradation of its binding partner S100A10/p11. J Biol Chem. 2008 Jul 11;283(28):19192-200.

[39] Surette AP, Madureira PA, Phipps KD, Miller VA, Svenningsson P, Waisman DM. Regulation of fibrinolysis by S100A10 in vivo. Blood. 2011;118(11):3172 -3181.

[40] O'Connell PA, Surette AP, Liwski RS, Svenningsson P, Waisman DM. S100A10 regulates plasminogen-dependent macrophage invasion. Blood. 2010 Aug 19;116(7):113646.

[41] Tofler GH, D'Agostino RB, Jacques PF, Bostom AG, Wilson PWF, Lipinska I, et al. Association between increased homocysteine levels and impaired fibrinolytic potential: potential mechanism for cardiovascular risk. Thromb Haemost. 2002 Nov;88(5): 799-804.

[42] Hajjar KA. Homocysteine: a sulph'rous fire. J Clin Invest. 2001 Mar;107(6):663-4.

[43] Karolczak K, Olas B. Mechanism of action of homocysteine and its thiolactone in hemostasis system. Physiol Res Acad Sci Bohemoslov. 2009;58(5):623-33.

[44] Lentz SR. Mechanisms of homocysteine-induced atherothrombosis. J Thromb Haemost JTH. 2005 Aug;3(8):1646-54.

[45] Cai H, Harrison DG. Endothelial dysfunction in cardiovascular diseases: the role of oxidant stress. Circ Res. 2000 Nov 10;87(10):840-4.

[46] Zhang C, Cai Y, Adachi MT, Oshiro S, Aso T, Kaufman RJ, et al. Homocysteine induces programmed cell death in human vascular endothelial cells through activation of the unfolded protein response. J Biol Chem. 2001 Sep 21;276(38):35867-74.

[47] Jacobsen DW, Catanescu O, Dibello PM, Barbato JC. Molecular targeting by homocysteine: a mechanism for vascular pathogenesis. Clin Chem Lab Med CCLM FESCC. 2005;43(10):1076-83.

[48] Tousoulis D, Bouras G, Antoniades C, Marinou K, Miliou A, Papageorgiou N, et al. The activation of endothelin-1 pathway during methionine-induced homocysteinemia mediates endothelial dysfunction in hypertensive individuals. J Hypertens. 2010 May;28(5):925-30.

[49] Moshal KS, Sen U, Tyagi N, Henderson B, Steed M, Ovechkin AV, et al. Regulation of homocysteine-induced MMP-9 by ERK1/2 pathway. Am J Physiol Cell Physiol. 2006 Mar;290(3):C883-891.

[50] Dionisio N, Jardín I, Salido GM, Rosado JA. Homocysteine, intracellular signaling and thrombotic disorders. Curr Med Chem. 2010;17(27):3109-19.

[51] Khajuria A, Houston DS. Induction of monocyte tissue factor expression by homocysteine: a possible mechanism for thrombosis. Blood. 2000 Aug 1;96(3):966-72. 
[52] Ling Q, Hajjar KA. Inhibition of endothelial cell thromboresistance by homocysteine. J Nutr. 2000 Feb;130(2S Suppl):373S-376S.

[53] Hajjar KA. Homocysteine-induced modulation of tissue plasminogen activator binding to its endothelial cell membrane receptor. J Clin Invest. 1993 Jun;91(6):2873-9.

[54] Selhub J. Homocysteine metabolism. Annu Rev Nutr. 1999;19:217-46.

[55] Hajjar KA, Mauri L, Jacovina AT, Zhong F, Mirza UA, Padovan JC, et al. Tissue plasminogen activator binding to the annexin II tail domain. Direct modulation by homocysteine. J Biol Chem. 1998 Apr 17;273(16):9987-93.

[56] Félez J, Miles LA, Fábregas P, Jardí M, Plow EF, Lijnen RH. Characterization of cellular binding sites and interactive regions within reactants required for enhancement of plasminogen activation by tPA on the surface of leukocytic cells. Thromb Haemost. 1996 Oct;76(4):577-84.

[57] Jacovina AT, Deora AB, Ling Q, Broekman MJ, Almeida D, Greenberg CB, et al. Homocysteine inhibits neoangiogenesis in mice through blockade of annexin A2-dependent fibrinolysis. J Clin Invest. 2009 Nov;119(11):3384-94.

[58] Kang SS, Wong PW, Becker N. Protein-bound homocyst(e)ine in normal subjects and in patients with homocystinuria. Pediatr Res. 1979 Oct;13(10):1141-3.

[59] Dayal S, Chauhan AK, Jensen M, Leo L, Lynch CM, Faraci FM, et al. Paradoxical absence of a prothrombotic phenotype in a mouse model of severe hyperhomocysteinemia. Blood. 2012 Mar 29;119(13):3176-83.

[60] Dayal S, Wilson KM, Leo L, Arning E, Bottiglieri T, Lentz SR. Enhanced susceptibility to arterial thrombosis in a murine model of hyperhomocysteinemia. Blood. 2006 Oct 1;108(7):2237-43.

[61] Jakubowski H. Homocysteine in Protein Structure/Function and Human Disease: Chemical Biology of Homocysteine-containing Proteins. Springer; 2013.

[62] Yap S, Boers GHJ, Wilcken B, Wilcken DEL, Brenton DP, Lee PJ, et al. Vascular Outcome in Patients With Homocystinuria due to Cystathionine $\beta$-Synthase Deficiency Treated Chronically A Multicenter Observational Study. Arterioscler Thromb Vasc Biol. 2001 Dec 1;21(12):2080-5.

[63] Eikelboom JW, Lonn E, Genest J, Hankey G, Yusuf S. Homocyst(e)ine and Cardiovascular Disease: A Critical Review of the Epidemiologic Evidence. Ann Intern Med. 1999 Sep 7;131(5):363-75.

[64] Clarke R, Halsey J, Lewington S, Lonn E, Armitage J, Manson JE, et al. Effects of lowering homocysteine levels with $\mathrm{B}$ vitamins on cardiovascular disease, cancer, and cause-specific mortality: Meta-analysis of 8 randomized trials involving 37485 individuals. Arch Intern Med. 2010 Oct 11;170(18):1622-31. 
[65] Bønaa KH, Njølstad I, Ueland PM, Schirmer H, Tverdal A, Steigen T, et al. Homocysteine lowering and cardiovascular events after acute myocardial infarction. N Engl J Med. 2006 Apr 13;354(15):1578-88.

[66] Lonn E, Yusuf S, Arnold MJ, Sheridan P, Pogue J, Micks M, et al. Homocysteine lowering with folic acid and B vitamins in vascular disease. N Engl J Med. 2006 Apr 13;354(15):1567-77.

[67] Den Heijer M, Willems HPJ, Blom HJ, Gerrits WBJ, Cattaneo M, Eichinger S, et al. Homocysteine lowering by $\mathrm{B}$ vitamins and the secondary prevention of deep vein thrombosis and pulmonary embolism: A randomized, placebo-controlled, doubleblind trial. Blood. 2007 Jan 1;109(1):139-44.

[68] Study of the Effectiveness of Additional Reductions in Cholesterol and Homocysteine (SEARCH) Collaborative Group, Armitage JM, Bowman L, Clarke RJ, Wallendszus K, Bulbulia R, et al. Effects of homocysteine-lowering with folic acid plus vitamin B12 vs placebo on mortality and major morbidity in myocardial infarction survivors: a randomized trial. JAMA J Am Med Assoc. 2010 Jun 23;303(24):2486-94.

[69] O'Connell PA, Madureira PA, Berman JN, Liwski RS, Waisman DM. Regulation of S100A10 by the PML-RAR- $\alpha$ oncoprotein. Blood. 2011 Apr 14;117(15):4095-105.

[70] Menell JS, Cesarman GM, Jacovina AT, McLaughlin MA, Lev EA, Hajjar KA. Annexin II and bleeding in acute promyelocytic leukemia. N Engl J Med. 1999 Apr 1;340(13):994-1004.

[71] Liu Y, Wang Z, Jiang M, Dai L, Zhang W, Wu D, et al. The expression of annexin II and its role in the fibrinolytic activity in acute promyelocytic leukemia. Leuk Res. 2011 Jul;35(7):879-84.

[72] Puisieux A, Ji J, Ozturk M. Annexin II up-regulates cellular levels of p11 protein by a post-translational mechanisms. Biochem J. 1996 Jan 1;313 ( Pt 1):51-5.

[73] Mignatti P, Rifkin DB. Biology and biochemistry of proteinases in tumor invasion. Physiol Rev. 1993 Jan;73(1):161-95.

[74] Markus G, Kohga S, Camiolo SM, Madeja JM, Ambrus JL, Karakousis C. Plasminogen activators in human malignant melanoma. J Natl Cancer Inst. 1984 Jun;72(6): 1213-22.

[75] Tapiovaara H, Alitalo R, Vaheri A. Plasminogen activation on tumor cell surface and its involvement in human leukemia. Adv Cancer Res. 1996;69:101-33.

[76] Andreasen PA, Kjøller L, Christensen L, Duffy MJ. The urokinase-type plasminogen activator system in cancer metastasis: A review. Int J Cancer. 1997;72(1):1-22.

[77] Davis GE, Pintar Allen KA, Salazar R, Maxwell SA. Matrix metalloproteinase-1 and -9 activation by plasmin regulates a novel endothelial cell-mediated mechanism of 
collagen gel contraction and capillary tube regression in three-dimensional collagen matrices. J Cell Sci. 2001 Mar;114(Pt 5):917-30.

[78] Gong Y, Hart E, Shchurin A, Hoover-Plow J. Inflammatory macrophage migration requires MMP-9 activation by plasminogen in mice. J Clin Invest. 2008 Sep;118(9): 3012-24.

[79] Mazzieri R, Masiero L, Zanetta L, Monea S, Onisto M, Garbisa S, et al. Control of type IV collagenase activity by components of the urokinase-plasmin system: a regulatory mechanism with cell-bound reactants. EMBO J. 1997 May 1;16(9):2319-32.

[80] Pepper MS. Role of the Matrix Metalloproteinase and Plasminogen Activator-Plasmin Systems in Angiogenesis. Arter Thromb Vasc Biol. 2001 Jul 1;21(7):1104-17.

[81] Duffy MJ, O'siorain L, O'grady P, Devaney D, Fennelly JJ, Lijnen HJ. Urokinase-plasminogen activator, a marker for aggressive breast carcinomas. Preliminary report. Cancer. 1988;62(3):531-3.

[82] Ding Y, Zhang H, Zhong M, Zhou Z, Zhuang Z, Yin H, et al. Clinical significance of the uPA system in gastric cancer with peritoneal metastasis. Eur J Med Res. 2013 Aug 28;18(1):28.

[83] Kumano M, Miyake H, Muramaki M, Furukawa J, Takenaka A, Fujisawa M. Expression of urokinase-type plasminogen activator system in prostate cancer: Correlation with clinicopathological outcomes in patients undergoing radical prostatectomy. Urol Oncol Semin Orig Investig. 2009 Mar;27(2):180-6.

[84] Smith HW, Marshall CJ. Regulation of cell signalling by uPAR. Nat Rev Mol Cell Biol. 2010 Jan 1;11(1):23-36.

[85] Chiang Y, Davis RG, Vishwanatha JK. Altered expression of annexin II in human Bcell lymphoma cell lines. Biochim Biophys Acta. 1996 Oct 11;1313(3):295-301.

[86] Emoto K, Yamada Y, Sawada H, Fujimoto H, Ueno M, Takayama T, et al. Annexin II overexpression correlates with stromal tenascin-C overexpression: a prognostic marker in colorectal carcinoma. Cancer. 2001 Sep 15;92(6):1419-26.

[87] Emoto K, Sawada H, Yamada Y, Fujimoto H, Takahama Y, Ueno M, et al. Annexin II overexpression is correlated with poor prognosis in human gastric carcinoma. Anticancer Res. 2001 Apr;21(2B):1339-45.

[88] Vishwanatha JK, Chiang Y, Kumble KD, Hollingsworth MA, Pour PM. Enhanced expression of annexin II in human pancreatic carcinoma cells and primary pancreatic cancers. Carcinogenesis. 1993 Dec;14(12):2575-9.

[89] Choi K-S, Fogg DK, Yoon C-S, Waisman DM. p11 regulates extracellular plasmin production and invasiveness of HT1080 fibrosarcoma cells. FASEB J Off Publ Fed Am Soc Exp Biol. 2003 Feb;17(2):235-46. 
[90] Zhang L, Fogg DK, Waisman DM. RNA interference-mediated silencing of the S100A10 gene attenuates plasmin generation and invasiveness of Colo 222 colorectal cancer cells. J Biol Chem. 2004 Jan 16;279(3):2053-62.

[91] Rust R, Visser L, van der Leij J, Harms G, Blokzijl T, Deloulme JC, et al. High expression of calcium-binding proteins, S100A10, S100A11 and CALM2 in anaplastic large cell lymphoma. Br J Haematol. 2005 Dec;131(5):596-608.

[92] Ito Y, Arai K, Nozawa R, Yoshida H, Higashiyama T, Takamura Y, et al. S100A10 expression in thyroid neoplasms originating from the follicular epithelium: contribution to the aggressive characteristic of anaplastic carcinoma. Anticancer Res. 2007 Aug;27(4C):2679-83.

[93] Domoto T, Miyama Y, Suzuki H, Teratani T, Arai K, Sugiyama T, et al. Evaluation of S100A10, annexin II and B-FABP expression as markers for renal cell carcinoma. Cancer Sci. 2007 Jan;98(1):77-82.

[94] Nishiu M, Yanagawa R, Nakatsuka S, Yao M, Tsunoda T, Nakamura Y, et al. Microarray analysis of gene-expression profiles in diffuse large B-cell lymphoma: identification of genes related to disease progression. Jpn J Cancer Res Gann. 2002 Aug; 93(8):894-901.

[95] Shang J, Zhang Z, Song W, Zhou B, Zhang Y, Li G, et al. S100A10 as a novel biomarker in colorectal cancer. Tumour Biol J Int Soc Oncodevelopmental Biol Med. 2013 Jul 5 ;

[96] Remmelink M, Mijatovic T, Gustin A, Mathieu A, Rombaut K, Kiss R, et al. Identification by means of cDNA microarray analyses of gene expression modifications in squamous non-small cell lung cancers as compared to normal bronchial epithelial tissue. Int J Oncol. 2005 Jan 1;26(1):247-58.

[97] Tan Y, Ma S-Y, Wang F-Q, Meng H-P, Mei C, Liu A, et al. Proteomic-based analysis for identification of potential serum biomarkers in gallbladder cancer. Oncol Rep. 2011 Oct;26(4):853-9.

[98] Leśniak W. Epigenetic regulation of S100 protein expression. Clin Epigenetics. 2011 Aug 1;2(2):77-83.

[99] Sharma MR, Koltowski L, Ownbey RT, Tuszynski GP, Sharma MC. Angiogenesis-associated protein annexin II in breast cancer: selective expression in invasive breast cancer and contribution to tumor invasion and progression. Exp Mol Pathol. 2006 Oct;81(2):146-56.

[100] Sharma M, Blackman MR, Sharma MC. Antibody-directed neutralization of annexin II (ANX II) inhibits neoangiogenesis and human breast tumor growth in a xenograft model. Exp Mol Pathol. 2012 Feb;92(1):175-84. 
[101] Zhang H-J, Yao D-F, Yao M, Huang H, Wang L, Yan M-J, et al. Annexin A2 silencing inhibits invasion, migration, and tumorigenic potential of hepatoma cells. World J Gastroenterol WJG. 2013 Jun 28;19(24):3792-801.

[102] Wu B, Zhang F, Yu M, Zhao P, Ji W, Zhang H, et al. Up-regulation of Anxa2 gene promotes proliferation and invasion of breast cancer MCF-7 cells. Cell Prolif. 2012 Jun;45(3):189-98.

[103] Zhao P, Zhang W, Tang J, Ma X-K, Dai J-Y, Li Y, et al. Annexin II promotes invasion and migration of human hepatocellular carcinoma cells in vitro via its interaction with HAb18G/CD147. Cancer Sci. 2010 Feb;101(2):387-95.

[104] Wang Y, Lv H, Li Z, Li C, Wu X. Effect of shRNA mediated down-regulation of Annexin A2 on biological behavior of human lung adencarcinoma cells A549. Pathol Oncol Res POR. 2012 Apr;18(2):183-90.

[105] Wang C-Y, Chen C-L, Tseng Y-L, Fang Y-T, Lin Y-S, Su W-C, et al. Annexin A2 silencing induces G2 arrest of non-small cell lung cancer cells through p53-dependent and -independent mechanisms. J Biol Chem. 2012 Sep 21;287(39):32512-24.

[106] Chiang Y, Schneiderman MH, Vishwanatha JK. Annexin II expression is regulated during mammalian cell cycle. Cancer Res. 1993 Dec 15;53(24):6017-21.

[107] Bao H, Jiang M, Zhu M, Sheng F, Ruan J, Ruan C. Overexpression of Annexin II affects the proliferation, apoptosis, invasion and production of proangiogenic factors in multiple myeloma. Int J Hematol. 2009 Sep 1;90(2):177-85.

[108] Zhang J, Guo B, Zhang Y, Cao J, Chen T. Silencing of the annexin II gene down-regulates the levels of S100A10, c-Myc, and plasmin and inhibits breast cancer cell proliferation and invasion. Saudi Med J. 2010 Apr;31(4):374-81.

[109] Chiang Y, Rizzino A, Sibenaller ZA, Wold MS, Vishwanatha JK. Specific down-regulation of annexin II expression in human cells interferes with cell proliferation. Mol Cell Biochem. 1999 Sep 1;199(1-2):139-47.

[110] Madureira PA, Hill R, Miller VA, Giacomantonio C, Lee PWK, Waisman DM. Annexin A2 is a novel cellular redox regulatory protein involved in tumorigenesis. Oncotarget. 2011 Dec;2(12):1075-93.

[111] Cooke MS, Evans MD, Dizdaroglu M, Lunec J. Oxidative DNA damage: mechanisms, mutation, and disease. FASEB J. 2003 Jul 1;17(10):1195-214.

[112] Mah L-J, El-Osta A, Karagiannis TC. $\gamma \mathrm{H} 2 \mathrm{AX}$ : a sensitive molecular marker of DNA damage and repair. Leukemia. 2010 Apr;24(4):679-86.

[113] Madureira PA, Hill R, Lee PWK, Waisman DM. Genotoxic agents promote the nuclear accumulation of annexin A2: role of annexin A2 in mitigating DNA damage. PloS One. 2012;7(11):e50591. 
[114] Siveen KS, Kuttan G. Role of macrophages in tumour progression. Immunol Lett. 2009 Apr 27;123(2):97-102.

[115] Lissbrant IF, Stattin P, Wikstrom P, Damber JE, Egevad L, Bergh A. Tumor associated macrophages in human prostate cancer: relation to clinicopathological variables and survival. Int J Oncol. 2000 Sep;17(3):445-51.

[116] Phipps KD, Surette AP, O'Connell PA, Waisman DM. Plasminogen Receptor S100A10 Is Essential for the Migration of Tumor-Promoting Macrophages into Tumor Sites. Cancer Res. 2011 Nov 1;71(21):6676 -6683.

[117] Oh C-W, Hoover-Plow J, Plow EF. The role of plasminogen in angiogenesis in vivo. J Thromb Haemost JTH. 2003 Aug;1(8):1683-7.

[118] Myrvang HK, Guo X, Li C, Dekker LV. Protein interactions between surface Annexin A2 and S100A10 mediate adhesion of breast cancer cells to microvascular endothelial cells. FEBS Lett. 2013 Aug 27; 
